\title{
Diferenciação in vitro de células-tronco mesenquimais da medula óssea de cães em precursores osteogênicos ${ }^{1}$
}

\author{
Sílvia A.F. Lima*2,3, Thaila I. Wodewotzky², João F. Lima-Neto² ${ }^{2}$ Patrícia C.B. Beltrão-Braga ${ }^{3}$ \\ e Fernanda C.L. Alvarenga ${ }^{2}$
}

\begin{abstract}
Lima S.A.F., Wodewotzky T.I., Lima-Neto J.F., Beltrão-Braga P.C.B. \& Alvarenga F.C.L. 2012. [In vitro differentiation of mesenchimal stem cells of dogs into osteogenic precursors.] Diferençiação in vitro de células-tronco mesenquimais da medula óssea de cães em precursores osteogênicos. Pesquisa Veterinária Brasileira 32(5):463-469. Departamento de Reprodução Animal e Radiologia Veterinária, Faculdade de Medicina Veterinária e Zootecnia, Universidade Estadual Paulista, Campus de Botucatu, Distrito de Rubião Júnior s/n, Botucatu, SP 18618-970, Brazil. E-mail: silviavet@usp.br

The aim of our research was to evaluate the potential for osteogenic differentiation of mesenchimal stem cells (MSC) obtained from dog bone marrow. The MSC were separated using the Ficoll method and cultured under two different conditions: DMEM low glucose or DMEM/F12, both containing L-glutamine, 20\% of FBS and antibiotics. MSC markers were tested, confirming CD44+ and CD34- cells with flow cytometry. For osteogenic differentiation, cells were submitted to four different conditions: Group 1, same conditions used for primary cell culture with DMEM supplemented media; Group 2, same conditions of Group 1 plus differentiation inductors Dexametazone, ascorbic acid and $\beta$-glicerolphosphate. Group 3, Cells cultured with supplemented DMEM/F12 media, and Group 4, same conditions as in Group 3 plus differentiation inductors Dexametazone, ascorbic acid and $\beta$-glicerolphosphate. The cellular differentiation was confirmed using alizarin red and imunostaining with SP7/Osterix antibody. We observed by alizarin staining that calcium deposit was more evident in cells cultivated in DMEM/F12.Furthermore, by SP/70sterix antibody immunostaining we obtained 1:6 positive cells when using DMEM/F12 compared with 1:12 for low-glucose DMEM. Based on our results, we conclude that the medium DMEM/ F12 is more efficient for induction of differentiation of mesenchymal stem cells in canine osteogenic progenitors. This effect is probably due to the greater amount of glucose in the medium and the presence of various amino acids.
\end{abstract}

INDEX TERMS: Mesenchymal stem cell, osteogenic differentiation, dog.

RESUMO.- 0 objetivo principal da nossa pesquisa foi avaliar o potencial de diferenciação osteogênica de células-tronco mesenquimais (MSC) obtidas da medula óssea do cão. As MSC foram separadas pelo método Ficoll e cultivadas sob duas condições distintas: DMEM baixa glicose ou DMEM/

\footnotetext{
${ }^{1}$ Recebido em 4 de agosto de 2011.

Aceito para publicação em 1 de março de 2012

${ }^{2}$ Departamento de Reprodução Animal e Radiologia Veterinária, Faculdade de Medicina Veterinária e Zootecnia, Universidade Estadual Paulista (Unesp), Campus de Botucatu, Distrito de Rubião Júnior s/n, Botucatu, SP 18618-970, Brasil.

${ }^{3}$ Setor de Anatomia dos Animais Domésticos e Silvestres, Departamento de Cirurgia, Faculdade de Medicina Veterinária e Zootecnia, Universidade de São Paulo (USP), Av. Prof. Dr. Orlando Marques de Paiva 87, Cidade Universitária. São Paulo, SP 05508 270, Brasil. *Autor para correspondência: safl_001@hotmail.com ou silviavet@usp.br
}

F12, ambos contendo L-glutamina, 20\% de SFB e antibióticos. Marcadores de MSC foram testados, confirmando células CD44+ e CD34- através da citometria de fluxo. Para a diferenciação osteogênica, as células foram submetidas a quatro diferentes condições: Grupo 1, as mesmas condições utilizadas para a cultura de células primárias com os meios DMEM baixa glicose suplementado; Grupo 2, as mesmas condições do Grupo 1, mais os indutores de diferenciação dexametasona, ácido ascórbico e b-glicerolfosfato; Grupo 3, células cultivadas com meios DMEM/F12 suplementado; e Grupo 4, nas mesmas condições que no Grupo 3, mais indutores de diferenciação de dexametasona, ácido ascórbico e b-glicerolfosfato. A diferenciação celular foi confirmada através da coloração com alizarin red e da imunomarcação com o anticorpo SP7/Osterix. Nós observamos através da 
coloração com alizarin red que o depósito de cálcio foi mais evidente nas células cultivadas em DMEM/F12. Além disso, usando a imunomarcação com o anticorpo SP/70sterix obtivemos positividade em 1:6 células para o Meio DMEM/ F12 comparada com 1:12 para o meio DMEM-baixa glicose. Com base nos nossos resultados concluímos que o meio DMEM/F12 é mais eficiente para a indução da diferenciação de células-tronco mesenquimais caninas em promotores osteogênicos. Este efeito provavelmente ocorre em decorrência da maior quantidade de glicose neste meio, bem como da presença de diversos aminoácidos.

TERMOS DE INDEXAÇÃO: Células-tronco mesenquimais, diferenciação osteogênica, cão, célula-tronco dos animais.

\section{INTRODUÇÃO}

As CTMs possuem baixa taxa de crescimento in vivo, mas apresentam alta capacidade de regeneração e habilidade de se diferenciar em várias linhagens celulares de origem mesenquimal. Elas substituem células que foram perdidas pela senilidade ou por injúrias (Conrad \& Huss 2005).

As CTMs foram caracterizadas inicialmente in vitro pela sua aderência e morfologia fibroblastóide (Chen et al. 2008), mas alguns marcadores da superfície celular têm sido utilizados para selecionar ou excluir CTMs provenientes de populações celulares heterogêneas. Desta forma, diversos resultados têm mostrado que as CTMs apresentam inúmeros marcadores imunofenotípicos. Entretanto, estes marcadores não são específicos, ocorrendo em outros tipos celulares. Desta forma, o fenótipo antigênico das células-tronco progenitoras hematopoiéticas e mesenquimais não é único, mas emprestam características de células mesenquimais, endoteliais, epitelial, e outras.

A imunofenotipagem consiste na separação de populações distintas de células, cujos antígenos de superfície são marcados com anticorpos específicos (Roitt et al. 1999). Na caracterização de células-tronco obtidas da medula óssea ou cordão umbilical são utilizados anticorpos conjugados a fluorocromos excitáveis, os quais reconhecem antígenos específicos de membrana. No estudo pioneiro sobre células-tronco do sangue do cordão umbilical, Nakage (2005) quantificou as células-tronco hematopoéticas do sangue do cordão umbilical de cães neonatos pela expressão do anticorpo monoclonal canino CD34, marcado com PE (McSweeney et al. 1998) e pelo protocolo ISHAGE de citometria de fluxo (Sutherland et al. 1996), demonstrando ser este último um método simples, rápido, sensível e eficaz para avaliação de células-tronco de cães. Essa técnica vem sendo muito ultilizada para a caracterização das células-tronco do cordão umbilical de cães (Zucconi et al. 2010, Brólio et al. 2011). A citometria de fluxo é um recurso emergente na Clínica Médica Veterinária, que permite uma análise rápida, objetiva e quantitativa de células em suspensão (Faldyna et al. 2001). Wenceslau et al. (2011) realizou um estudo sobre células progenitoras mesenquimais de tecidos fetais caninos, entre eles saco vitelino, fígado e medula óssea, e notaram que os esses tecidos possuem marcadores de CTM, porém há uma variação funcional no potencial de diferenciação notadas durante as fases do desenvolvimento.
A quantificação das células-tronco CD34+ pela citometria de fluxo nos animais domésticos é possível na espécie canina, devido à produção de anticorpos monoclonais específicos para CD34 canino por McSweeney et al. (1998). A marcação com anticorpo monoclonal canino CD34 e sua respectiva contagem por meio da análise no citômetro de fluxo permitem a identificação e a quantificação das CTH na medula óssea (McSweeney et al. 1998, Bruno et al. 1999, Bruno et al. 2001, Hartnett et al. 2002). As células-tronco mesenquimais seriam então identificadas através de seu poder adesivo e de crescimento em cultivo, bem como pela marcação negativa para o CD34, HLA-DR (MHC class II), CD4 (co-receptor de célula T), CD14 (receptor de lipopolissacarídeo), CD25 (receptor de interleucina-2) e CD45 (antígeno de leucócitos). Além disso estas células também devem apresentar marcação positiva por diversos outros anticorpos, como o HLA-ABC (MHC class I), CD90 (Thy-1), CD105 (Endoglin/SH2), CD106 (VCAM-1), CD73 (SH-3), CD166 (ALCAM), SSEA-4, Stro-1, SH-4 (FOX et al. 2007), CD29 (receptor de fibronectina), CD44, CD49a-f (PHINNEY \& PROCKOP 2007), CD133 e Oct4 (Tondreau et al. 2005). Múltiplos métodos têm sido estudados para a restauração de defeitos ósseos no campo da cirurgia reconstrutiva craniomaxilofacial e cirurgia ortopédica. Os enxertos ósseos favorecem a consolidação óssea, provendo uma fonte osteogênica, osteocondutiva, osteoindutiva e, dependendo do tipo, suporte mecânico (Fitch et al. 1997). Uma abordagem alternativa é a implantação de células vivas que são diretamente osteogênicas. De acordo com o conceito de engenharia de tecidos, é possível regenerar vários tecidos usando células vivas em um arcabouço apropriado, entre eles, o tecido ósseo (Boo et al. 2002).

Diversas pesquisas têm relatado a diferenciação in vitro de culturas de CTMs para a linhagem osteoblásticas pela suplementação do meio de cultura com dexametasona e ácido ascórbico (Jaiswal et al. 1997, Maniatopoulos et al. 1988, Pittenger et al. 1999, Boo et al. 2002, Tropel et al. 2004). Uma vez neste meio de cultivo, as CTMs adultas entram em uma cascata de desenvolvimento, definida pela aquisição de uma morfologia osteoblástica cuboidal, indução transitória de produção de fosfatase alcalina, expressão de mRNAs de proteína de matriz óssea e deposição de matriz extracelular de hidroxiapatita mineralizada (Bruder et al. 1998).

A dexametasona (Dex) induz diferenciação osteoblástica em diversos modelos de cultura de células. Alguns estudos investigaram o efeito do tratamento contínuo e descontínuo com Dex sobre a diferenciação de células de medula óssea humana (BMSC) mostrando que, a presença contínua de Dex não parece ser necessária para o desenvolvimento do fenótipo osteoblástico. Contudo, a Dex deve estar presente após a primeira passagem para permitir a diferenciação osteoblástica expressa por proliferação celular reduzida e aumento da atividade de ALP e da formação de matriz mineralizada. (Beloti \& Rosa 2005).

0 ácido ascórbico (AsA) funciona como um cofator na hidrolização dos resíduos de prolina e de lisina no colágeno (Aronow et al. 1990, Prockop \& Kivirikko 1995), bem como levando ao aumento da síntese de matrizes protéicas do 
osso não-colagenoso. Desta forma este componente é adicionado rotineiramente a culturas de células osteogênicas, sendo considerada essencial (Otsuka et al. 2000).

Jaiswal et al. (1997) cultivaram células-tronco mesenquimais em presença de dexametazona, ácido ascórbico e $\beta G P$, observando uma dramática mudança na morfologia celular, acompanhada por um aumento significante na atividade fosfatase alcalina após 4 dias em cultivo. Além disso, no dia 16 de cultivo, os autores observaram também o depósito de uma matriz calcificada na superfície da placa de cultura, a qual foi evidenciada pelo coloração de von Kossa.

Durante a diferenciação osteoblastica é essencial a expressão de fatores de transcrição como o NFATc1 (nuclear factor of activated $T$ cells) e o Osterix. A expressão do NFATc1 estimula a ativação do osterix através da ação de um promotor de colágeno do tipo 1 (col1a1). 0 NFAT e o osterix formam um complexo que se liga ao DNA induzindo a transcrição de fatores específicos. Osterix exerce papel fundamental na diferenciação de células mesenquimais em osteoblastos (Komori et al. 1997, Ducy et al. 2000), sendo também um fator de transcrição de grande importância no processo de formação óssea (Nakashima et al. 2002).

Os modelos experimentais de células-tronco em cães têm propiciado informações relevantes para transplantes de células-tronco em humanos e informações pré-clínicas importantes tanto para a terapêutica da medicina humana como veterinária.

O objetivo geral deste experimento foi estudar a caracterização de células-tronco mesenquimais obtidas a partir de medula óssea do úmero de cães, induzindo a diferenciação celular in vitro para tecido ósseo. Para tanto, foram estados diferentes meios de cultura contendo fatores indutores de diferenciação osteoblástica, dexametasona, ácido ascórbico e $\beta$-glicerolfosfato.

\section{MATERIAL E MÉTODOS}

Para a colheita e isolamento das células-tronco mesenquimais, foram utilizados 6 cães adultos, hígidos, pesando em média 20 $\mathrm{kg}$, proveniente de proprietários frequentadores do hospital veterinário e do Canil da Faculdade de Medicina Veterinária e Zootecnia da Unesp, Campus de Botucatu. Os animais foram preparados para a punção da medula óssea, a qual foi realizada no úmero direito.

Inicialmente cada animal foi tranqüilizado com acepromazina na dose de $0,05 \mathrm{mg} / \mathrm{kg}$ pela via intramuscular. Decorridos 15 minutos, os animais foram posicionados em decúbito lateral direito e a veia cefálica esquerda foi canulada para receber solução fisiológica de cloreto de sódio 0,9\%, na dose de $20 \mathrm{ml} / \mathrm{kg} /$ hora. Em seguida, a anestesia geral foi induzida com propofol, na dose de 6-8 mg/kg pela via intravenosa. Após tricotomia e anti-sepsia da região da articulação escápulo-umeral direita, uma agulha de biópsia de medula óssea foi introduzida no tubérculo maior do úmero até atingir o canal medular. À agulha foi acoplada a uma seringa descartável de $20 \mathrm{ml}$ contendo $1 \mathrm{ml}$ de heparina sódica, na qual, por meio de gradiente de pressão negativo, foram coletados em média $5 \mathrm{ml}$ de medula óssea de cada animal.

Após a coleta da medula óssea, o sangue foi centrifugado a 1500 rpm por 10 minutos para retirada do soro e gordura. 0 material obtido foi ressuspendido na proporção 1/1 em DMEM baixa glicose sem soro com GlutaMAX ${ }^{\mathrm{TM}}$-I (Gibco, 10567-014). Deste foi utilizado um volume de $4 \mathrm{~mL}$, que foi transferido para um outro tubo (Tubo para centrifugação com fundo cônico, 15mL; TPP - Techno Plastic Products AG; Cód. 000292), contendo 4mL de Ficoll-Paque (densidade 1.077g/mL, Amersham Biosciences; diluição Ficoll:meio de 1:1), sendo então centrifugado a $1500 \mathrm{rpm}$ durante 40 minutos à temperatura ambiente. Após coletar o anel de células na interface Ficoll-células e ressuspender em meio DMEM sem soro, o material foi novamente centrifugado a $1.500 \mathrm{rpm}$ durante 10 minutos. Este passo foi repetido por duas vezes para total retirada do Ficoll. Posteriormente à lavagem, o pellet foi ressuspendido em $1 \mathrm{ml}$ de DMEM com $20 \%$ de soro fetal bovino inativado, e as células contadas em câmera de Neubauer. As células foram plaqueadas em frascos de $25 \mathrm{~cm}^{2}$ (Tissue Culture Flask, $25 \mathrm{~cm}^{2}$ - T-25 (Sarstedt, 83.1810.300) com 5ml de meio DMEM ou DMEM/F12 com L-glutamina (Gibco 11765-054) e 20\% SFB (Gibco 12657029) contendo $100 \mathrm{UI} / \mathrm{mL}$ Penicilina/100 $\mu \mathrm{g} / \mathrm{mL}$ Estreptomicina (Sigma, P3539) e 3,0 $\mu \mathrm{g} / \mathrm{mL}$ Anfotericina B (Sigma, A9528). 0 meio de cultura foi trocado a cada 4 ou 5 dias. 0 repique das células foi realizado quando se atingiu uma confluência de aproximadamente $80 \%$ que ocorre em média depois de 15 dias de cultivo primário usando Tripsina 0,25\% (10x) (LGC, BR30045-01).

As cultura de células foi testada por citometria de fluxo usando marcadores para células-tronco mesenquimais CD44 (Abcan, ab41478) e não mesenquimais CD34 (Abcan, ab63985).

As células-tronco mesenquimais foram diferenciadas in vitro com a utilização de promotores de diferenciação para tecido ósseo. Para tanto, $3 \times 10^{3}$ células mesenquimais $/ \mathrm{cm}^{2}$ foram transferidas para placas de cultura de tecido de $10 \mathrm{~cm}^{2}$ contendo $5 \mathrm{ml}$ de meio de acordo com os seguintes grupos.

No Grupo 1, as células foram cultivadas em DMEM - baixa glicose (Gibco, 10567-014) acrescido de L-glutamina e 20\% de SFB (Gibco, 12657-029) contendo $100 \mathrm{UI} / \mathrm{mL}$ Penicilina/100 $\mu \mathrm{g} / \mathrm{mL}$ Estreptomicina (Sigma, P3539) e 3,0 $\mathrm{gg} / \mathrm{mL}$ Anfotericina B (Sigma, A9528).

No Grupo 2, as células foram cultivadas no mesmo meio do Grupo 1, acrescido do Kit da Chemicon (Cat. No. SCR028) de indutores de diferenciação osteogênica contendo Dexametazona 0,1 $\mu \mathrm{M}$; Ácido ascórbico 0,3mM e $\beta$-Glicerolfosfato $10 \mathrm{mM}$.

No Grupo 3, foram cultivadas em meio a base de DMEM/F12 acrescido de L-glutamina (F-12 + L-glutamina (Gibco, 11765-054) e $20 \%$ de SFB contendo penicilina, estreptomicina e anfoterecina-B.

No Grupo 4, as células foram cultivadas no mesmo meio do Grupo 3, acrescido o kit de indutores de diferenciação.

As células foram mantidas no meio de indução por 7 dias, de acordo com o protocolo do fabricante. As culturas foram mantidas em estufa de cultivo com atmosfera úmida contendo $5 \%$ de $\mathrm{CO}_{2}$ em ar e humidade relativa de $100 \%$.

Para análise da diferenciação das CTMs foi avaliada a morfologia celular, a marcação com o Alizarin Red (Kit Chemicon, SCR028), que marca a presença de depósitos de cálcio pelas células diferenciadas. Para confirmação da diferenciação foi realizada a marcação com SP7/Osterix (Abcam) que indica a diferenciação para osteoblastos.

Para o teste do Alizarin red, o meio de cada garrafa de cultivo foi descartado e substituído por álcool $70 \%$ durante 30 minutos a $4{ }^{\circ} \mathrm{C}$, para fixação da amostra. Após o tempo de fixação, o álcool foi descartado e as células lavadas com PBS por duas vezes. Em seguida, foi adicionado o Alizarin Red. Após um tempo de marcação de 30 minutos as células foram lavadas com PBS por duas vezes para retirada do excesso de corante.

Para a marcação com o SP7/Osterix, as células foram ressuspendidas com tripsina sintética, lavadas duas vezes com PBS para retirada do excesso de tripsina e a concentração ajustada para $1 \times 10^{6} \mathrm{cell} / \mathrm{mL}$. Uma alicota de $100 \mu \mathrm{l}$ (100 mil células) foi retirada 
e transferida para um microtubo contendo o anticorpo primário (concentração de 1:100). 0 tempo de incubação foi de 1 hora, após o qual foi adicionado o anticorpo secundário (1:100 - Alexa-fluor 514) e incubado por mais uma hora. Para leitura, montou-se uma alíquota da solução sobre lamina e lamínula e o exame foi feito em microscópio de fluorescência equipado com filtro Azul, sob aumento de 400x. A estimativa do índice de células marcadas foi feita contando-se 10 campos por lâmina onde, o número total de células era contado em campo claro e o número de células marcadas era contado, no mesmo campo, sob luz fluorescente.

\section{RESULTADOS}

O tempo de cultivo primário necessário para obtenção da confluência não diferiu entre os grupos sendo em média de 15 dias para o grupo cultivado em DMEM/F12 e de 16 dias para o DMEM-baixa glicose (Fig.1). Ao final do cultivo primário a caracterização fenotípica foi realizada em uma alíquota de cada amostra. A imuno fenotipagem por citometria de fluxo mostrou que, ao final do cultivo primário, $68,5 \%$ das células apresentavam marcação CD34- e 97,1\% marcação CD44+ (Fig.2). Esta característica imunofenotipica indica que uma boa parcela da população de células em cultivo é constituída por células mesenquimais. Os resultados alcançados foram obtidos pela análise dos gráficos apresentados.

Somente foi observada indução da diferenciação celular nos grupos tratados com os promotores, independente do meio de cultivo utilizado.

Após 7 dias da indução da diferenciação observou-se a mudança da morfologia celular no grupo tratado com DMEN baixa glicose. Neste grupo houve modificação da morfologia celular de aspecto fusiforme (típico de MSC) para cubóide. Esta modificação é considerada um indicativo da ocorrência de diferenciação celular e está de acordo com o encontrado por Jaiswal et al. (1997) que cultivaram células-tronco mesenquimais em presença de dexametazona, ácido ascórbico e glicerol 2-fosfato, observando uma dramática mudança na morfologia celular. Por outro lado nas células cultivadas em meio DMEM/F12 a modificação da morfologia celular não foi tão evidente, o que indicaria um menor grau de diferenciação neste grupo (Fig.3).

Entretanto, a análise dos resultados com o marcador Alizarin Red, demonstrou a ocorrência de um maior acú-

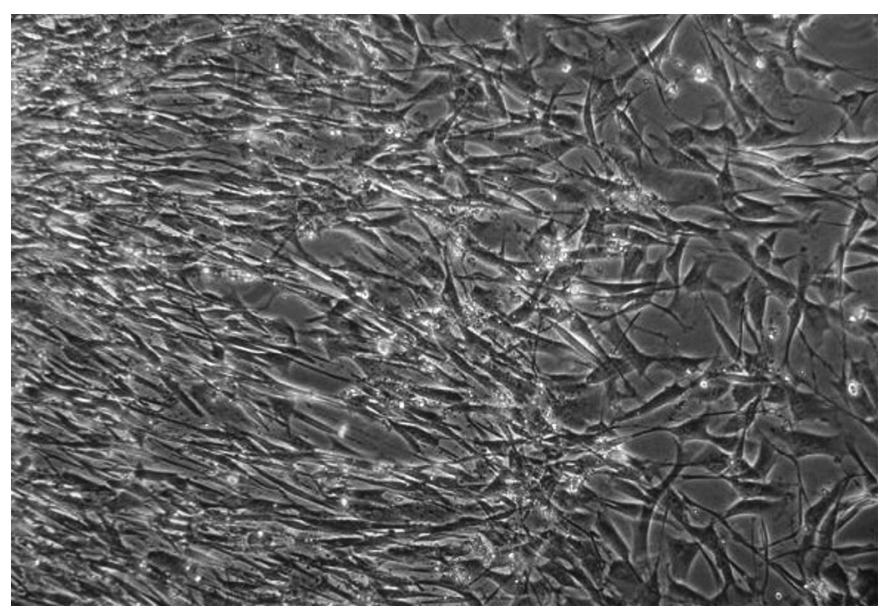

Fig.1. Cultura de células-tronco mesenquimais de cão, em cultivo por 15 dias. Microscópio óptico de contraste de fase, 400x.
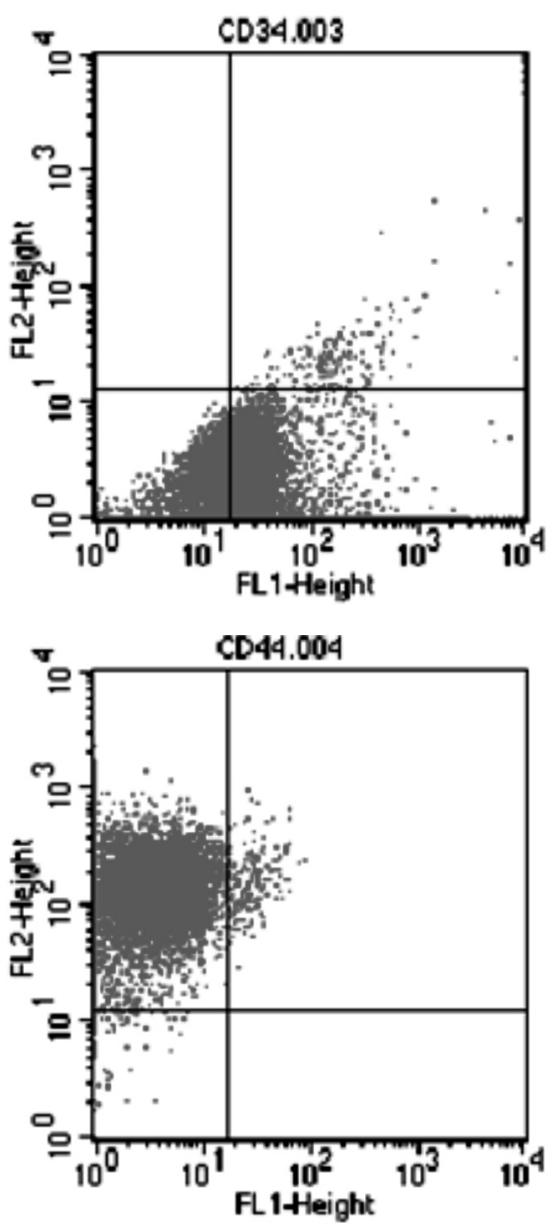

Fig.2. Gráfico obtido a partir da análise da citometria de fluxo mostrando as porcentagens de células marcadas com os anticorpos CD34 e CD44, nas amostras do cultivo primário de células da medula óssea.

mulo de cálcio no grupo cultivado com DMEM/F12, o que indica que estas células se diferenciaram em osteoblastos funcionais. Por outro lado no grupo de células cultivadas em meio DMEM baixa glicose a marcação foi significativamente menos evidente (Fig.4). Estes resultados contradizem os dados observados quando avaliou-se a morfologia celular. De acordo com Pittenger et al. (1999) células mesenquimais humanas cultivadas em presença de dexametazona e ácido ascórbico passaram a apresentar depósitos de Calcio indicando sua diferenciação para osteoblastos. Este método de avaliação do potencial osteogênico das células em cultivo é mais eficiente, em comparação com a simples análise da morfologia celular, uma vez que indica uma mudança no metabolismo celular mimetizando sua função in vivo.

Os dados obtidos após a coloração com Alizarim red foram confirmados com o uso da marcação com SP7/Osterix. O Osterix é um fator de transcrição expresso por osteoblastos e a sua presença confirma a diferenciação celular. No presente experimento 1:6 células avaliadas foram marcadas pelo osterix no meio DMEM/F12 (Fig,5). Esta marcação foi mais alta que a observada nas células cultivadas em DMEM baixa glicose, onde somente 1:12 células apresentaram a presença do osterix. 

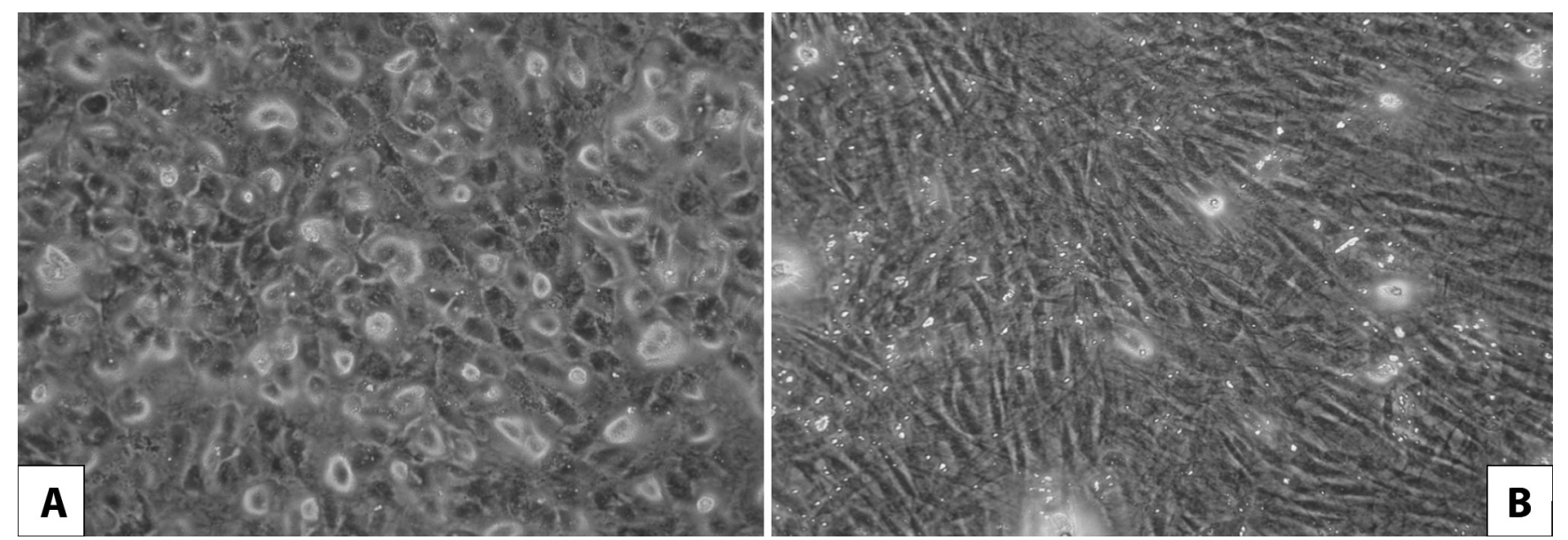

Fig.3. Cultura de células-tronco mesenquimais de cão após 7 dias de cultivo (A) com meio DMEM baixa glicose ou (B) DMEM/F12, ambos suplementados com os fatores indutores de osteogênenese. Microscópio óptico de contraste de fase, 400x.
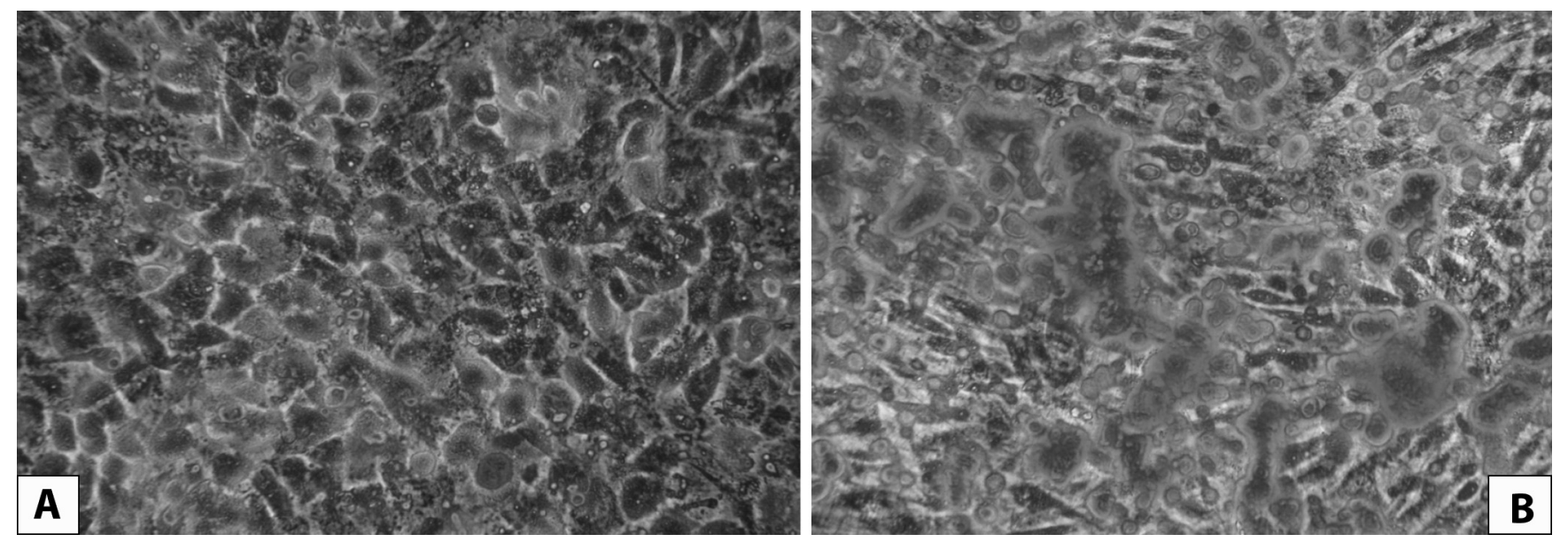

Fig.4. Cultura de células-tronco mesenquimais de cão cultivadas (A) em meio DMEM ou (B) DMEM/F12, ambos suplementados com indutores de diferenciação osteogênica e marcadas com Alizarim Red, respectivamente. Microscópio óptico de contraste de fase, 400x.

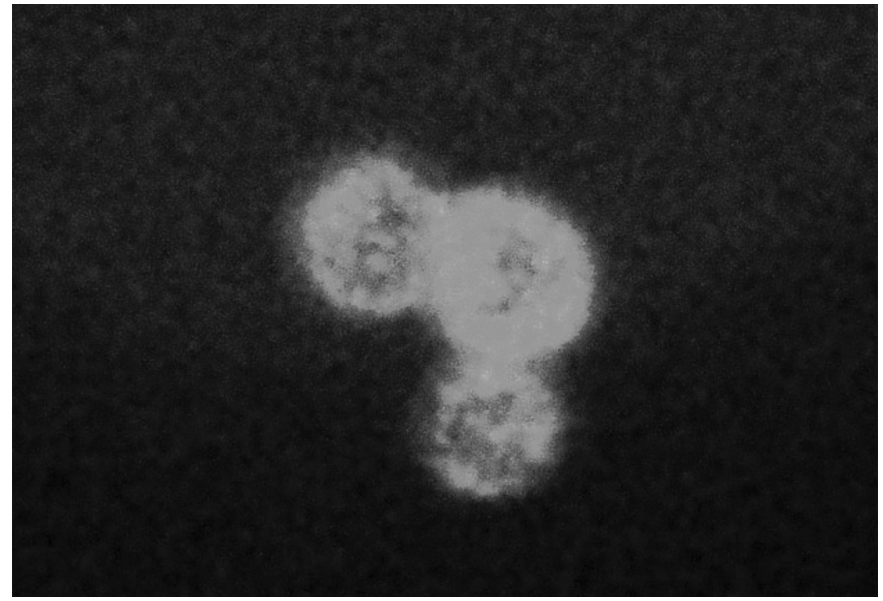

Fig.5. Marcação das células cultivadas com DMEM/F12 pelo SP7/ Osterix. Microscópio de fluorescência de alta resolução, 630x.

\section{DISCUSSÃO}

A composição do meio de cultivo influencia diretamente o potencial de diferenciação de células mesenquimais in vitro (Pittenger et al. 1999). Diversas pesquisas têm relatado a diferenciação in vitro de culturas de células-tronco mesenquimais para a linhagem osteoblásticas pela suplementação do meio de cultura com dexametasona e ácido ascórbico (Pittenger et al. 1999, Tropel et al. 2004). Uma vez neste meio de cultivo, as células-tronco mesenquimais adultas entram em uma cascata de desenvolvimento, definida pela aquisição de uma morfologia osteoblástica cuboidal, indução transitória de produção de fosfatase alcalina, expressão de mRNAs de proteína de matriz óssea e deposição de matriz extracelular de hidroxiapatita mineralizada (Bruder et al. 1998).

Confirmamos a diferenciação celular com a marcação pelo depósito de cálcio no meio extracelular através da coloração pelo Alizarin Red observando-se um maior acúmulo de cálcio no grupo cultivado com DMEM/F12 em relação ao grupo de células cultivadas em meio DMEM baixa glicose. Estes resultados contradizem os dados observados quando se avaliou a morfologia celular. De acordo com Pittenger et al. (1999) células mesenquimais humanas cultivadas em presença de dexametazona e ácido ascórbico passaram a apresentar depósitos de cálcio indicando sua diferenciação para osteoblastos. Este método de avaliação do potencial 
osteogênico das células em cultivo é mais eficiente, em comparação com a simples análise da morfologia celular, uma vez que indica uma mudança no metabolismo celular mimetizando sua função in vivo.

De acordo com Ramoshebi et al. (2002) existem três parâmetros fundamentais na engenharia tecidual óssea, os quais vão determinar a capacidade de osteoindução: presença de sinais osteoindutores solúveis, viabilidade das células-tronco mesenquimais indiferenciadas em responder e se diferenciar em células formadoras de osso e produção de matriz extracelular adequada. As células-tronco mesenquimais, quando em cultura e na presença de citocinas ativadoras de osso, sofrem osteopoiese, processo esse que envolve a proliferação e a maturação de células precursoras primitivas até a formação de osteoblastos funcionais.

Inúmeros experimentos descritos na literatura demonstram a diferenciação e indução osteogênica de células-tronco mesenquimais, com o uso de um meio de cultura padrão, suplementado com baixas concentrações de ácido ascórbico, dexametasona e $\beta$-glicerolfosfato. Nestas condições, múltiplos marcadores osteogênicos celulares são expressos incluindo, por exemplo, o osterix (Komori et al. 1997, Ducy et al. 2000). De fato, no presente experimento, o uso deste marcador confirmou os dados obtidos com a coloração por Alizarin Red, realçando o maior potencial de diferenciação das células cultivadas em meio DMEM/F12.

A diferenciação celular é controlada por uma cascata de eventos moleculares envolvidos na regulação gênica através da ação de uma variedade de hormônios, citocinas e fatores de crescimento (Ducy \& Karsenty 1998). A dexametazona atua influenciando a proliferação e diferenciação de células da linhagem osteogênica através da alteração da via de sinalização de fatores de crescimentos e hormônios (Cooper et al. 2008). 0 ácido ascórbico é necessário para a síntese e depósito da matriz de colágeno (Xiao et al. 1997). $0 \beta$-glicerolfosfato promove a mineralização in vitro pelo mecanismo de modulação da atividade metabólica de células ósseas servindo como fonte local de íons e fosfatos inorgânicos (Chung et al. 1992).

0 meio DMEM baixa glicose é um meio que contem altas concentrações de cálcio $(1,8 \mathrm{mM})$ e uma baixa concentração de glicose $(1 \mathrm{~g} / \mathrm{L})$ em comparação com o meio Ham's F12 que embora contenha concentrações de cálcio semelhantes ao DMEM, apresenta um maior teor de glicose $(1,8 \mathrm{~g} / \mathrm{L})$. Desta forma a associação do meio DMEM baixa glicose ao Ham F12 resultou em um meio mais rico em nutrientes, o que parece ter influenciado o potencial de diferencial das CTM caninas em cultivo. Estes resultados estão de acordo com Wu et al. (2009) que observaram que a diferenciação de células do periósteo de cães em osteoblastos foi mais eficiente utilizando-se um meio enriquecido (DMEM) em comparação com um mais pobre (RPMI 1640).

\section{CONCLUSÕES}

Através dos resultados do presente experimento foi possível concluir que o meio DMEM/F12 é mais eficiente para a indução da diferenciação osteogênica de células-tronco mesenquimais caninas, o que foi confirmado com o marcador Alizarim Red e com o SP7/Osterix. Este efeito provavelmente ocorre em decorrência da maior quantidade de glicose neste meio, bem como da presença de diversos aminoácidos.

Além disso, foi observado que a avaliação da mudança de morfologia das células em cultivo não é um bom parâmetro para analisar seu potencial de diferenciação in vitro.

\section{REFERÊNCIAS}

Aronow M.A., Gerstenfeld L.C., Owen T.A., Tassinari M.S., Stein G.S. \& Lian J.B. 1990. Factors that promote progressive development of the osteoblast phenotype in cultured fetal rat calvaria cells. J. Cell Physiol. 143:213-221

Beloti M.M. \& Rosa A.L. 2005. Osteoblast differentiation of human bone marrow cells under continuous and discontinuous treatment with dexamethasone Braz. Dent. J. 16(2):156-161.

Boo J.S., Yamada Y., Okazaki Y., Hibino Y., Okada K., Hata K.I., Bruder S.P. \& Fox B.S. 1999. Tissue engineering of bone-cell based strategies. Clin. Orthop. Relat. Res. 367:S68-S83.

Brólio M.P., Vidane A.S., Zomer H.D., Wenceslau C.V., Ozório J.J., Martins D.S., Miglino M.A. \& Ambrósio C.E. 2011. Morphological characterization of the progenitor blood cells in canine and feline umbilical cord. Microsc. Res. Tech. 2011 Dec 1. doi: 10.1002/jemt.21123.

Bruno B. 1999. CD34+ selected bone marrow grafts are radioprotective and establish mixed chimerism in dogs given high dose total body irradiation. Transplantation 68(3):338-344.

Bruno B. 2001. Purified canine CD34+Lin- marrow cells transduced with retroviral vectors give rise to long-term multilineage hematopoiesis. Biol. Blood Marrow Transpl. 7(10):543-551.

Chung C.H., Golub E.E., Forbes E., Tokuoka T. \& Shapiro I.M. 1992. Mechanism of action of beta-glycerophosphate on bone cell mineralization. Calcif. Tissue Int. 51(4):305-311.

Conrad C. \& Huss R. 2005. Adult stem cell lines in regenerative medicine and reconstructive surgery. J. Surgical Res. 124:201-208.

Cooper M.S., Hewison M. \& Stewart P.M. 1999. Glucocorticoid activity, inactivity and theosteoblast. J. Endocrinol. 163(2):159-164.

Ducy P. \& Karsenty G.1998. Genetic control of cell differentiation in the skeleton. Curr. Opin. Cell Biol. 10(5):614-619.

Ducy P., Schinke T. \& Karsenty G. 2000. The osteoblast: A sophisticated fibroblast under central surveillance. Science 289:1501-1504.

Faldyna M. 2001. Lymphocyte subsets in peripheral blood of dogs: A flow cytometric study. Vet. Immunol. Immunopathol. 82(1/2):23-37.

Hartnett B.J. 2002. Transplantation of X-linked sever combined immunodeficient dogs with CD34+ bone marrow cells. Biol. Blood Marrow Transpl. 8(4):188-197.

Jaiswal O., Haynesworth S.E., Caplan A.I. \& Bruder S.P. 1997. Osteogenic differentiation of purified, culture-expanded Human mesenchymal stem cells: In vitro. J. Cellular Biochem. 64:295-312.

Komori T., Yagi H., Nomura S., Yamaguchi A., Sasaki K., Deguchi K., Shimizu Y., Bronson R.T., Gao Y.H., Inada M., Sato M., Okamoto R., Kitamura Y., Yoshiki S. \& Kishimoto T. 1997. Targeted disruption of Cbfa1 results in a complete lack of bone formation owing to maturational arrest of osteoblasts. Cell 89:755-764.

Maniatopoulos C., Sodek J. \& Melcher A.H. 1988. Bone formation in vitro by stromal cells obtained from bone marrow of young adult rats. J. Cell Tissue Res. 254(2):317-330.

McSweeney P.A. 1998. Characterization of monoclonal antibodies that recognize canine CD34. Blood 91:1977-1986.

Nakage A.P.M. 2005. Influência do tipo de parto na hematologia do cordão umbilical de cães. Ciência Rural 35:377-380.

Nakashima X., Zhou G., Kunkel Z., Zhang J., Deng R., Behringer B. \& Crombrugghe D. 2002. The novel zinc finger-containing transcription factor osterix is required for osteoblast differentiation and bone formation. Cell 108(1):17-29. 
Otsuka E., Kato Y., Hirose S. \& Hagiwara H. 2000. Role of ascorbic acid in the osteoclast formation: Induction of osteoclast differentiation factor with formation of the extracellular collagen matrix. Endocrinology 141:3006-3011.

Phinney D.G. \& Prockop D.J. 2007. Concise Review: Mesenchymal stem/ multipotent stromal cells: the state of transdifferentiation and modes of tissue repair-current views. Stem Cells 25(11):2896-2902.

Pittenger M.F., Mackay A.M., Beck S.C., Jaiswal R.K., Douglas R., Mosca J.D., Moorman M.A., Simonetti D.W., Craig S. \& Marshak D.R. 1999. Multilineage potential of adult human mesenchymal stem cells. Science 284(5411):143-147.

Prockop D.J. \& Kivirikko K.I. 1995. Collagens: Molecular biology, diseases, and potentials for therapy. Annu. Rev. Biochem. 64:403-434.

Ramoshebi L.N., Matsaba T.N., Teare J., Renton L., Patton J. \& Ripamonti U. 2002. Tissue engineering: TGF-beta superfamily members and delivery systems in bone regeneration. Expert. Rev. Mol. Med. 4(20):1-11.

Sutherland D.R., Yeo E.L., Stewart A.K., Nayar R., DiGiusto R., Zanjani E., Hoffman R. \& Murray L.J. 1996. Identification of CD34(+) subsets after glycoprotease selection: Engraftment of CD34(+)Thy-1(+)Lin(-) stem cells in fetal sheep. Exp. Hematol. 24(7):795-806.
Tropel P., Noel D., Platet N., Legrand P., Benabid A.L. \& Berger F. 2004. Isolation and characterization of mesenchymal stem cells from adult mouse bone marrow. Exp. Cell Res. 295:395-406.

Wenceslau C.V., Miglino M.A., Martins D.S., Ambrósio C.E., Lizier N.F., Pignatari G.C. \& Kerkis I. 2011. Mesenchymal progenitor cells from canine fetal tissues: Yolk sac, liver, and bone marrow. Tissue Eng. A 17(17/18):2165-2176.

Wu X., Lin M., Li Y., Zhao X. \& Yan F. 2009. Effects of DMEM and RPMI 1640 on the biological behavior of dos periosteum-derived cells. Int. J. Cell Culture Biotechnol. (Doi: 10.1007/s10616-009-9200-5)

Xiao G., Cui Y., Ducy P., Karsenty G. \& Franceshi R.T. 1997. Ascorbic acid-dependentactivation of the osteocalcin promoter in MC3T3-E1 preosteoblasts: Requirement for collagen matrix synthesis and the presence of an intact OSE2 sequence. Mol. Endocrinol. 11(8):1103-1113.

Yoshikawa T., Sugiura Y. \& Ueda M. 2002. Tissue-engineered bone using mesenchymal stem cells and a biodegradable scaffold. J. Craniofacial Surg. 13(2):231-239.

Zucconi E., Vieira N.M., Bueno D.F., Secco M., Jazedje T., Ambrosio C.E., Passos-Bueno M.R., Miglino M.A. \& Zatz M. 2010. Mesenchymal stem cells derived from canine umbilical cord vein: A novel source for cell therapy studies. Stem Cells Dev. 19(3):395-402. 